\title{
Comparison of the extraction efficiencies of four different solvents used in trace metal digestion of selected soils within Abakaliki, Nigeria
}

\section{OMAKA, NDUKAKU OMAKA ${ }^{1}$, OFFOR, IFEANYI FRANCIS ${ }^{1}$, CHUKWU, EBUBE REBECCA $^{2}$, EWUZIE, UGOCHUKWU ${ }^{3} *$}

\author{
${ }^{I}$ Department of Chemistry, Federal University, Ndufu Alike, Ikwo, P.M.B. 1010, Ebonyi State \\ ${ }^{2}$ Department of Industrial Chemistry, Ebonyi State University, P.M.B. 053, Abakaliki, Ebonyi \\ ${ }^{3}$ Department of Industrial Chemistry, Abia State University, P.M.B 2000, Uturu, Abia State \\ *Corresponding author: ewuzieug@gmail.com
}

KEY WORDS: Extraction, Soils, Pollution, Trace metals, Abakaliki

\begin{abstract}
Soil pollution by trace metals is one of the major global environmental challenges facing us today. Extraction methods are key to predicting plant uptake of trace metals from soil. This work seeks to compare the extraction efficiencies of EDTA, DTPA, $\mathrm{HNO}_{3} / \mathrm{HClO}_{4}$ and $\mathrm{HCl} / \mathrm{HNO}_{3}$ used in the digestion of soil samples collected from 11 different locations ( 7 farmlands, 2 waste dumpsites and 2 sections of a mechanic workshop) within Abakaliki metropolis, between August and September 2007. Concentrations of 7 selected trace metals $(\mathrm{Pb}, \mathrm{Zn}, \mathrm{Mn}, \mathrm{Ni}, \mathrm{Cd}, \mathrm{Cu}$ and $\mathrm{Fe})$ were determined in the digested soil samples using atomic absorption spectrophotometer. The concentrations $(\mathrm{mg} / \mathrm{kg})$ range, irrespective of sampling sites were: $\mathrm{Pb}(2.85-43.07$; 1.42-11.49; 3.83-131.90; 1.98-184.12), Zn (0.02-3.98; $0.01-0.79 ; 2.25-13.22 ; 0.15-39.45), \mathrm{Mn}(1.33-78.83 ; 0.38-14.85 ; 1.02-66.24 ; 0.84-104.39), \mathrm{Ni}$ (1.15-14.10; 0.07-2.57; 2.09-49.70; 5.10-92.72), Cd (0.03-2.79; 0.01-0.61;0.25-9.20;0.15$3.68), \mathrm{Cu}(1.59-79.96 ; 0.65-14.33 ; 1.02-184.68 ; 1.60-134.10), \mathrm{Fe}(6.62-149.44 ; 0.39-12.22$; 44.95-375.27; 7.48-548.32) using EDTA, DTPA, $\mathrm{HNO}_{3} / \mathrm{HClO}_{4}$ and $\mathrm{HCl} / \mathrm{HNO}_{3}$ respectively as extractants. Results revealed that all extractants showed strong positive correlation in bringing only $\mathrm{Cd}$ into solution. ANOVA depicted no significant difference in mean trace metals contents of soils from mechanic workshops as extracted with all solutions, while other locations did. For risk assessment, only $\mathrm{Cd}, \mathrm{Ni}$ and $\mathrm{Pb}$ had their values within the regulatory limits, whereas others were above the limits in all samples from different locations.@ JASEM
\end{abstract}

\section{http://dx.doi.org/10.4314/jasem.v19i2.8}

\section{INTRODUCTION}

Trace metal contamination of virgin soils is a major environmental challenge facing most parts of the world today (Doumett et al., 2008; Nouri et al., 2006). Adequate assessment of potential risks posed by trace metals entering the human food chain directly or indirectly through plants requires the knowledge of plant metal concentrations and the behavior of trace metals found inside the plant (Eded, 2012). However, close monitoring of plants can pose some difficulties; hence it may be preferable to monitor soil systems, which are avenues through which plants uptake nutrients including trace metals. Some metals are essential nutrients needed for normal functioning of the body while others are toxic to human health even at low concentrations. For instance, $\mathrm{Mn}, \mathrm{Fe}, \mathrm{Ca}$ and $\mathrm{Mo}$ are important micronutrients needed in the body whereas others like $\mathrm{Zn}, \mathrm{Ni}, \mathrm{Cu}, \mathrm{V}, \mathrm{Co}$ and $\mathrm{Cr}$ though useful to living cells can become toxic when certain threshold limits are exceeded. However, some other metals like As, $\mathrm{Hg}$, $\mathrm{Sb}, \mathrm{Cd}, \mathrm{Pb}$ and $\mathrm{U}$ have no nutritional value and are toxic to humans and aquatic animals (Sun et al., 2001).

While many compounds such as organic molecules are more or less biodegradable, metal ions are nonbiodegradable and can be retained in the ecosystem indefinitely (Ancalulia, 1999). The pollution effect and toxicity of trace metals in soil can be described in terms of their solubility and bioavailability. Bioavailability is the key to assessing the potential toxicity of metals and their compounds because it depends on biological and physicochemical properties of metals, their ions and their compounds (Duffus, 2001). The existence of high concentration of trace metals in the soils pose potential health risks to those utilizing it, but the extent of risk involved is conditioned by the biological availability of the trace metals. The fraction of metals in soil considered as 
bioavailable is that fraction found in dissolved phase and available for accumulation by organisms. Thus, soils rich in solids that retain metals under insoluble forms shall pose no toxicological threat to organisms (Chapman, 1996). Factors affecting metal bioavailability include $\mathrm{pH}$, redox potential, soil texture, clay content, organic matter, presence of cations and anions in solutions etc. (Rieuwerts et al., 1998).

Several researches are ongoing to study the complicated plant-soil interaction, which often involves the use of bioavailability to estimate available metal fractions using two main extraction procedures namely: single extraction and sequential extraction (Kim and Fergusson, 1991). In this study, focus will be on single extraction procedures as it is more selective and less cumbersome to carry out than sequential extraction (Peijnenburg et al., 2007). Ethylenediammine tetraacetic acid (EDTA) and Diethylenetriammine pentaacetic acid (DTPA) are synthetic chelating agents that have often been used to estimate potential availability and mobility of metals (Antunovic et al., 2003). EDTA shows good affinity for acidic soils but poor affinity for neutral and alkaline soils (Kovacevic et al., 2002). In contrast, DTPA has good affinity for neutral and alkaline soils but poor affinity for acidic soils (Feng et al., 2005).

Ebonyi State is rich in solid minerals like iron ores, gypsum etc and as a result, deposits of trace metals are abundant in the state. Natural and anthropogenic processes going on in the environment can lead to increased concentrations of these heavy metals with their attendant health effects (O'Conor, 1988). Single extractions investigated in this study were strong acid digestions by $\mathrm{HNO}_{3} / \mathrm{HClO}_{4}$ and aqua regia $\left(\mathrm{HCl} / \mathrm{HNO}_{3}\right)$ for the determination of pseudo-total trace metal concentrations and synthetic acid (EDTA and DTPA) extractions for the determination of exchangeable metal concentrations.

The major aim of this work is to compare the trace metal extraction efficiencies of 4 selected reagents (EDTA, EPTA, $\mathrm{HNO}_{3} / \mathrm{HClO}_{4}$ and $\mathrm{HCl} / \mathrm{HNO}_{3}$ ) used in the digestion of soil samples from different parts of Ebonyi State. Other objectives include: to compare the trace metals results obtained with stipulated guidelines for metals in soils set by the National Environmental Standards and Regulatory Agency (NESREA), United Kingdom Environment Agency (UKEA) and World Health Organization (WHO) and to highlight the possible health implications associated with living close to the sites under investigation, if any.

\section{MATERIALS AND METHODS}

Description of study area: Abakaliki is the capital city of Ebonyi State, Nigeria, and lies between longitude $8^{0} 06^{\circ} \mathrm{E}$ and latitude $6^{0} 20^{\circ} \mathrm{N}$. The climate is of tropical humid type characterized by occasional heavy rainfall with accompanying winds (Awoke, 2004). Soil samples were collected from 11 different locations within Abakaliki ranging from farmlands and waste dumpsites to mechanic workshop. The study sites include 7 farmlands (PRESCO rice farmPRF, CAS Campus farm-CRF, Rice Mill farm-RMF, Ishieke Campus farm-ICF, Nnorom Street rice farmNMSF, Nna Street farm-NSF and Ogbaga Road farm-ORF), 2 waste dumpsites (Azuiyiokwu dumpsite-ADS and Timber shed dumpsite-TDS) and 2 strategic locations within a Mechanic workshop (AMWA and B-MWB).

Sample collection and pretreatment: Ten different subsamples were collected randomly from each of the selected study sites. Sampling of the topsoil up to 0$30 \mathrm{~cm}$ depth was done using a soil auger and later transferred into labelled pre-clean polythene bags for onward transportation to the laboratory. On getting to the laboratory, each of the subsamples from a particular site was mixed together to form composite sample.

Soil samples were dried in an oven (Model No: DHG$9030(\mathrm{~A}))$ at $110^{\circ} \mathrm{C}$ for 2 hours. The dried samples were then passed through a $1 \mathrm{~mm}$ plastic sieve in order to remove leaf debris and small stones. The samples were then pulverized using a plastic mortar and pestle and later sieved through a sieve of $25 \mu \mathrm{m}$ mesh size (Yongming, 2006).

Quality assurance: Hydrochloric acid $(37 \% \mathrm{w} / \mathrm{v})$, Nitric acid $(68 \% \mathrm{w} / \mathrm{v})$, Perchloric acid $(70 \% \mathrm{w} / \mathrm{v})$, Triethanolamine (TEA), Disodium

Ethylenediammine tetraacetic acid $\left(\mathrm{Na}_{2}\right.$ EDTA: $99.0 \%$ w/w), Disodium Diethylenetriammine pentaacetic acid $\left(\mathrm{Na}_{2} \mathrm{DTPA}\right)$ and Calcium chloride used were of analytical grade (Sigma-Aldrich, Germany) and were prepared using deionized water. Unless otherwise stated, all reagents were stored at $4^{0} \mathrm{C}$ and brought out from storage at least one hour before use. Sample containers and glassware were first rinsed with deionized water, then soaked in liquid soap solution for 12 hours, rinsed with deionized water and then soaked with $10 \% \mathrm{HNO}_{3}$ overnight. This eliminates adsorption unto the surfaces of the containers thus, minimizing contamination (Omaka, 2010). Reagent blank determinations were used to correct the instrument readings.

\section{OMAKA, NDUKAKU OMAKA ${ }^{l}$, OFFOR, IFEANYI FRANCIS ${ }^{l}$, CHUKWU, EBUBE REBECCA ${ }^{2}$, EWUZIE, UGOCHUKWU ${ }^{3} *$}


Samples extraction procedures and analysis: $10 \mathrm{~g}$ of dried soil sample was shaken with $50 \mathrm{ml}$ of $0.05 \mathrm{M}$ EDTA (pH 7.0) for 60 minutes on a rotary shaker. Extract was clarified by passage through Whatman No. 42 filter paper. For DTPA extraction, same weight was weighed into a clean polypropylene vessel, 20ml of $0.005 \mathrm{M}$ DTPA (pH 7.3) extractant was added and the mixture was shaken in a rotary shaker for 2 hours. After 2 hours, the solution was centrifuged at $2000 \mathrm{rev} / \mathrm{min}$ and then filtered with Whatman No. 42 filter paper. Both single extractions were carried out as described by Lindsay and Norvell (1978), with slight modification.

For $\mathrm{HNO}_{3} / \mathrm{HClO}_{4}$ Extraction, $0.5 \mathrm{~g}$ of dried soil sample was weighed into a clean vessel and $5 \mathrm{ml}$ of concentrated $\mathrm{HNO}_{3}$ was added. The mixture was then boiled for 15 minutes (for oxidation to occur) and allowed to cool. $2.5 \mathrm{ml}$ of $70 \% \mathrm{HClO}_{4}$ was then added and the mixture boiled gently until dense white fumes appeared. After cooling, $10 \mathrm{ml}$ of distilled water was added to the mixture which was then boiled, cooled and filtered through Whatman No. 42 filter paper.

For $\mathrm{HNO}_{3} / \mathrm{HCl}$ Extraction, 1g of dried soil sample was weighed into a clean vessel and $10 \mathrm{ml}$ mixture of hot $\mathrm{HNO}_{3} / \mathrm{HCl}$ (1:3 ratio) was added. The solution was thereafter filtered through Whatman No. 42 filter paper and filtrate diluted to $40 \mathrm{ml}$ using distilled water.
All filtrates were subsequently analyzed for the determination of trace metals concentration using Phoenix-986 (Biotech Engineering Management Co. Ltd. UK) flame atomic absorption spectrophotometer.

Statistical evaluation: Statistical analyses of data were carried out using SPSS 16.0 for windows (SPSS Inc., Polar Engineering and Consulting, 2007) and Excel 2007 statistical package programs. Analysis of variance test $(95 \%$ confidence interval) was conducted to test for significance between the trace metal level and the choice of extraction solvent and sample location. Two-tailed correlation analyses were also performed on amount of trace metals extracted against various solutions. Significant relationship was ascertained at the 0.05 and 0.01 levels. The use of principal component analysis (PCA) in this study was to visually explore the principal attributes of the analytical data and distribution of trace metals concentrations in soil, which will be difficult to recognize with tables alone.

\section{RESULTS AND DISCUSSION}

Trace metals concentration: The contents of the studied trace metals of soils from dump sites, mechanic workshops as well as farmlands were presented in Tables 1, 2 and 3 respectively. Also presented in Table 4 was the comparison of trace metals content with regulatory standards.

Table 1. Trace metal contents $(\mathrm{mg} / \mathrm{kg}$ ) of soil from dump sites with respect to extractants

\begin{tabular}{|c|c|c|c|c|c|c|c|c|}
\hline Site & Extractant & $\mathrm{Zn}$ & $\mathrm{Cu}$ & $\mathrm{Pb}$ & $\mathrm{Ni}$ & $\mathrm{Cd}$ & $\mathrm{Mn}$ & $\mathrm{Fe}$ \\
\hline \multirow{4}{*}{ TDS } & EDTA & 3.98 & 33.54 & 43.07 & 8.73 & 0.27 & 78.83 & 22.98 \\
\hline & DTPA & 0.43 & 7.54 & 4.94 & 2.57 & 0.10 & 3.54 & 12.22 \\
\hline & $\mathrm{HNO}_{3} / \mathrm{HCl}$ & 3.05 & 35.33 & 55.69 & 16.11 & 0.32 & 7.47 & 176.08 \\
\hline & $\mathrm{HNO}_{3} / \mathrm{HClO}_{4}$ & 39.45 & 41.94 & 63.07 & 57.00 & 0.35 & 104.39 & 412.42 \\
\hline \multirow{4}{*}{ ADS } & EDTA & 0.65 & 17.33 & 12.64 & 4.79 & 0.05 & 14.90 & 101.76 \\
\hline & DTPA & 0.08 & 3.52 & 2.24 & 0.45 & 0.01 & 14.85 & 3.21 \\
\hline & $\mathrm{HNO}_{3} / \mathrm{HCl}$ & 7.04 & 16.50 & 25.59 & 16.00 & 9.20 & 10.64 & 225.49 \\
\hline & $\mathrm{HNO}_{3} / \mathrm{HClO}_{4}$ & 11.13 & 42.36 & 20.94 & 92.72 & 0.46 & 17.02 & 548.32 \\
\hline
\end{tabular}

Zinc: The Zn concentration of soils from dump sites, irrespective of the extractants ranged from 0.08 $39.45 \mathrm{mg} / \mathrm{kg}$. On the overall, the efficiency of the extractants in leaching out $\mathrm{Zn}$ as well as other metals from the soil was in the order $\mathrm{HNO}_{3} / \mathrm{HClO}_{4}>$ $\mathrm{HNO}_{3} / \mathrm{HCl}>\mathrm{EDTA}>\mathrm{DTPA}$. For the determination of the exchangeable $\mathrm{Zn}$, which was evaluated using EDTA and DTPA, result showed that the former was more effective in bringing $\mathrm{Zn}$ into solution than the latter. This observation was in agreement with the result of the study of McGrath, in which the mean concentrations of $\mathrm{Zn}$ were 5.36 and $3.37 \mathrm{mg} / \mathrm{kg}$ using EDTA and DTPA as extractants under similar conditions as ours (McGrath, 1996). On the other hand, Sabienë and Brazauskienë (2004) have stated that 0.05 EDTA ( $\mathrm{pH} 7$ ) is capable of extracting from the soil not only the heavy metals participating in the exchange processes, but also the heavy metals in carbonates and organic complexes (bound); thus, the higher efficiency of EDTA than DTPA in extracting not only $\mathrm{Zn}$, but also other metals augured well. However, the above range was higher than what was observed in soils from farmlands $(0.01-13.22 \mathrm{mg} / \mathrm{kg}$ ) and mechanic workshops $(0.11-8.19 \mathrm{mg} / \mathrm{kg})$. Furthermore, results showed the effectiveness of $\mathrm{HNO}_{3} / \mathrm{HClO}_{4}$ in extracting $\mathrm{Zn}$, as well as other metals from soil, which was demonstrated by its high $\mathrm{Zn}$ level than aqua regia. Although, in some sites, $\mathrm{Zn}$ leached with aqua regia was higher than that of $\mathrm{HNO}_{3} / \mathrm{HClO}_{4}$. This could however be as a result of

$$
\begin{gathered}
\text { OMAKA, NDUKAKU OMAKA }{ }^{l} \text {, OFFOR, IFEANYI FRANCIS }{ }^{l} \text {, CHUKWU, EBUBE REBECCA }{ }^{2}, \text { EWUZIE, } \\
\text { UGOCHUKWU }{ }^{3} *
\end{gathered}
$$


adsorption/desorption processes, in that the observation was quite rare.

Copper: High $\mathrm{Cu}$ concentrations $(\mathrm{mg} / \mathrm{kg})$ were recorded for mechanic workshops (2.01-40.11) and dumpsites (3.52-42.36) than in farmland (0.65184.68), and these exceeded NESREA standard for copper in soil. It was noticed that site RMF had exceptionally high $\mathrm{Cu}$ content, which might have resulted from dumping of $\mathrm{Cu}$ containing materials in the site during mulching of the rice farm. The high $\mathrm{Cu}$ content of soils from mechanic workshops and dumpsites might have resulted from electrical components such as wires in addition to waste oil, and according to Adelekan and Abegunde (2011), on copper rich soils, only a limited number of plants have a chance of survival. This could be responsible for the absence of vegetation around the automechanic workshops.

Table 2. Trace metal contents $(\mathrm{mg} / \mathrm{kg})$ of soil from mechanic workshops with respect to extractants

\begin{tabular}{ccccccccc} 
Site & Extractant & $\mathrm{Zn}$ & $\mathrm{Cu}$ & $\mathrm{Pb}$ & $\mathrm{Ni}$ & $\mathrm{Cd}$ & $\mathrm{Mn}$ & $\mathrm{Fe}$ \\
\hline \multirow{5}{*}{ MWA } & EDTA & 0.66 & 4.72 & 9.93 & 3.73 & $\mathrm{ND}$ & 41.75 & 113.41 \\
& $\mathrm{DTPA}$ & 0.11 & 2.01 & 2.73 & 0.14 & $\mathrm{ND}$ & 2.93 & 10.66 \\
& $\mathrm{HNO}_{3} / \mathrm{HCl}$ & 5.58 & 5.08 & 22.22 & 4.35 & $\mathrm{ND}$ & 66.24 & 179.44 \\
& $\mathrm{HNO}_{3} / \mathrm{HClO}$ & 5.86 & 7.08 & 18.85 & 5.10 & $\mathrm{ND}$ & 0.84 & 217.22 \\
& $\mathrm{EDTA}$ & 2.05 & 15.38 & 39.34 & 14.10 & 2.79 & 39.99 & 149.44 \\
$\mathrm{MVB}$ & $\mathrm{DTPA}$ & 0.54 & 14.33 & 3.06 & 2.44 & 0.61 & 0.90 & 1.16 \\
& $\mathrm{HNO}_{3} / \mathrm{HCl}$ & 8.19 & 39.70 & 54.48 & 49.70 & 3.70 & 24.61 & 375.27 \\
& $\mathrm{HNO}_{3} / \mathrm{HClO}_{4}$ & 0.15 & 40.11 & 62.48 & 59.92 & 3.68 & 74.44 & 7.48 \\
\hline
\end{tabular}

$\mathrm{ND}=$ Not detected. Instrument detection limit is $0.001 \mathrm{mg} / \mathrm{kg}$

Lead: The range of $\mathrm{Pb}$ concentrations $(\mathrm{mg} / \mathrm{kg})$ for dumpsites, farmlands and mechanic workshops were 2.24-63.07, 1.42-184.12 and 2.73-62.48. These were all below the UKEA standard limit, but exceeded the NESREA limit as illustrated in Table 4. The trend in $\mathrm{Pb}$ concentration was dumpsites> mechanic workshops> farmlands. Although, looking at the range in Table 4 might seem otherwise; but this was as a result of a farmland (RMF), that had exceptionally high $\mathrm{Pb}$ concentration. Again, EDTA was proved good extracting solution for $\mathrm{Pb}$ which had solubilized maximum concentration of $\mathrm{Pb}$ than DTPA. Yet, for pseudo-total $\mathrm{Pb}$ concentration, $\mathrm{HNO}_{3} / \mathrm{HClO}_{4}$ showed higher efficiency that aqua regia.

Nickel: Dumpsites contained Ni in the range of $0.45-$ $92.72 \mathrm{mg} / \mathrm{kg}$, followed by mechanic workshops $(0.14-59.92 \mathrm{mg} / \mathrm{kg})$ and then farmlands (0.07$46.65 \mathrm{mg} / \mathrm{kg}$ ). These values were within the UKEA standard limits for $\mathrm{Ni}$ in soil. The trend in efficiency of extractants was still $\mathrm{HNO}_{3} / \mathrm{HClO}_{4}>\mathrm{HNO}_{3} / \mathrm{HCl}>$ EDTA > DTPA. Lenntech (2009) pointed out that the nickel concentration in soil can be as low as 0.2 $\mathrm{mg} / \mathrm{kg}$ or as high as $450 \mathrm{mg} / \mathrm{kg}$, which is consistent with the concentration obtained for the studied sites.

Cadmium: The range of $\mathrm{Cd}$ concentrations $(\mathrm{mg} / \mathrm{kg})$ in dumpsites, mechanic workshops and farmlands were $0.01-9.20,0.00-3.28$ and $0.00-3.68$ respectively. All these were below the UKEA standard limit, but above the limit given by NESREA (Table 4). Again, the trend for extractants efficiency was DTPA $<$ EDTA<
$\mathrm{HNO}_{3} / \mathrm{HCl}<\mathrm{HNO}_{3} / \mathrm{HClO}_{4}$. $\mathrm{Cd}$ is highly toxic metal without any known beneficial effect for plants and animals. It enters the body through the gastrointestinal track by eating food products grown on contaminated soils, although smokers may receive a considerable part of their $\mathrm{Cd}$ intake by inhaling cigarette smoke (Corbett et al., 2002). Consequently, consumers of products from these farms had nothing to worry about $\mathrm{Cd}$ toxicity because the available (for plant uptake) $\mathrm{Cd}$, which was ascertained by EDTA and DTPA, were all below the UKEA and NESREA standard limits.

Manganese and Iron: The Mn content of dumpsites, farmlands and mechanic workshops irrespective of extractants ranged from 7.47-104.39, 0.38-77.37 and $0.84-74.44 \mathrm{mg} / \mathrm{kg}$ respectively. The WHO limit of $0.04 \mathrm{mg} / \mathrm{kg}$ was exceeded in all locations irrespective of extractant. High Mn contents were also reported by Idugboe and co-workers, which also exceeded the standard limit (Idugboe et al., 2014).

Table 2 depicted EDTA viability in extracting $\mathrm{Fe}$ from soils around the mechanic workshops, which was not so in other sites. This observation could be as a result of the forms in which Fe was present in the said site.

However, both WHO and NESREA standard limits were exceeded for all sampling sites. This calls for immediate concern in that, even EDTA extractable Fe in some sites were more than the standard limits. Nonetheless, other authors had also reported high $\mathrm{Fe}$ concentrations in automobile workshops and

\section{OMAKA, NDUKAKU OMAKA ${ }^{l}$, OFFOR, IFEANYI FRANCIS ${ }^{l}$, CHUKWU, EBUBE REBECCA ${ }^{2}$, EWUZIE, $U G O C H U K W U^{3} *$}


confirmed that most soils contain appreciable quantities of iron (Idugboe et al., 2014).

Table 3. Trace metal contents $(\mathrm{mg} / \mathrm{kg})$ of soil from farmlands with respect to extractant

\begin{tabular}{|c|c|c|c|c|c|c|c|c|}
\hline Site & Extractant & $\mathrm{Zn}$ & $\mathrm{Cu}$ & $\mathrm{Pb}$ & $\mathrm{Ni}$ & $\mathrm{Cd}$ & $\mathrm{Mn}$ & $\mathrm{Fe}$ \\
\hline \multirow{4}{*}{ ORF } & EDTA & 1.05 & 1.59 & 3.90 & 6.40 & 0.10 & 1.33 & 10.98 \\
\hline & DTPA & 0.71 & 0.92 & 1.42 & 0.62 & 0.01 & 9.15 & 4.49 \\
\hline & $\mathrm{HNO}_{3} / \mathrm{HCl}$ & 3.12 & 1.02 & 1.98 & 2.09 & 0.49 & 11.27 & 48.95 \\
\hline & $\mathrm{HNO}_{3} / \mathrm{HClO}_{4}$ & 2.66 & 1.60 & 13.63 & 8.91 & 0.23 & 17.76 & 87.91 \\
\hline \multirow{4}{*}{ NSF } & EDTA & 3.44 & 7.52 & 23.47 & 2.96 & ND & 4.11 & 7.28 \\
\hline & DTPA & 0.01 & 1.68 & 4.38 & 0.07 & ND & 0.38 & 0.39 \\
\hline & $\mathrm{HNO}_{3} / \mathrm{HCl}$ & 6.66 & 10.18 & 35.68 & 11.14 & 0.01 & 8.15 & 240.50 \\
\hline & $\mathrm{HNO}_{3} / \mathrm{HClO}_{4}$ & 11.16 & 17.04 & 56.00 & 28.91 & 0.03 & 7.29 & 14.21 \\
\hline \multirow{4}{*}{ RMF } & EDTA & 0.67 & 79.96 & 8.21 & 3.36 & 1.09 & 23.93 & ND \\
\hline & DTPA & 0.13 & 2.04 & 11.49 & 0.08 & 0.26 & 9.42 & 2.71 \\
\hline & $\mathrm{HNO}_{3} / \mathrm{HCl}$ & 13.22 & 184.68 & 184.12 & 25.43 & 1.66 & 6.48 & 326.79 \\
\hline & $\mathrm{HNO}_{3} / \mathrm{HClO}_{4}$ & 10.62 & 134.10 & 131.90 & 25.08 & 3.28 & 4.74 & 308.06 \\
\hline \multirow{4}{*}{ NMSF } & EDTA & 2.83 & 4.44 & 9.37 & 1.18 & 0.03 & 1.56 & 14.94 \\
\hline & DTPA & 0.20 & 0.65 & 1.98 & 0.69 & 0.02 & 10.04 & 4.33 \\
\hline & $\mathrm{HNO}_{3} / \mathrm{HCl}$ & 6.05 & 6.45 & 16.32 & 6.74 & 0.25 & 2.04 & 142.71 \\
\hline & $\mathrm{HNO}_{3} / \mathrm{HClO}_{4}$ & 6.87 & 5.22 & 24.45 & 7.79 & 0.48 & 2.45 & 188.22 \\
\hline \multirow{4}{*}{ PRF } & EDTA & 0.02 & 3.27 & 9.90 & 13.67 & 0.05 & 2.47 & 8.84 \\
\hline & DTPA & 0.16 & 2.27 & 5.66 & 1.04 & 0.01 & 13.55 & 3.83 \\
\hline & $\mathrm{HNO}_{3} / \mathrm{HCl}$ & 4.82 & 5.54 & 24.90 & 5.52 & 0.52 & 2.62 & 171.51 \\
\hline & $\mathrm{HNO}_{3} / \mathrm{HClO}_{4}$ & 7.64 & 6.08 & 25.65 & 10.87 & 0.15 & 2.51 & 193.98 \\
\hline \multirow{4}{*}{ CRF } & EDTA & 3.51 & 7.22 & 9.23 & 2.09 & ND & 3.42 & 6.62 \\
\hline & DTPA & 0.14 & 2.32 & 2.17 & 0.71 & 0.03 & 10.94 & 8.63 \\
\hline & $\mathrm{HNO}_{3} / \mathrm{HCl}$ & 7.88 & 8.70 & 26.24 & 6.86 & 0.76 & 2.65 & 268.76 \\
\hline & $\mathrm{HNO}_{3} / \mathrm{HClO}_{4}$ & 12.46 & 12.67 & 25.11 & 15.78 & 0.29 & 7.52 & 435.72 \\
\hline \multirow{4}{*}{ ICF } & EDTA & 1.45 & 1.25 & 2.85 & 1.15 & ND & 77.37 & 117.18 \\
\hline & DTPA & 0.79 & 0.81 & 1.62 & 0.99 & ND & 0.62 & 2.70 \\
\hline & $\mathrm{HNO}_{3} / \mathrm{HCl}$ & 2.25 & 1.54 & 13.84 & 3.60 & 0.18 & 1.02 & 44.95 \\
\hline & $\mathrm{HNO}_{3} / \mathrm{HClO}_{4}$ & 3.34 & 2.19 & 3.83 & 46.65 & 0.23 & 1.08 & 73.99 \\
\hline
\end{tabular}

$\mathrm{ND}=$ Not detected. Instrument detection limit is $0.001 \mathrm{mg} / \mathrm{kg}$

Table 4. Comparison of concentration $(\mathrm{mg} / \mathrm{kg})$ of trace metals in soil samples with national and international limits for metals in soils

\begin{tabular}{lcccccc}
\hline & & Present study & & & Limits & \\
& Dump site & Farm land & Mechanic village & UKEA & NESREA & WHO \\
\hline $\mathrm{Zn}$ & $0.08-39.45^{*}$ & $0.01-13.22$ & $0.11-8.19$ & - & 1.00 & 5.00 \\
$\mathrm{Cu}$ & $3.52-42.36$ & $0.65-184.68$ & $2.01-40.11$ & - & 1.00 & - \\
$\mathrm{Pb}$ & $2.24-63.07$ & $1.42-184.12$ & $2.73-62.48$ & 450.00 & 1.00 & - \\
$\mathrm{Ni}$ & $0.45-92.72$ & $0.07-46.65$ & $0.14-59.92$ & 130.00 & - & - \\
$\mathrm{Cd}$ & $0.01-9.20$ & $0.00-3.28$ & $0.00-3.68$ & 10.00 & 1.00 & - \\
$\mathrm{Mn}$ & $7.47-104.39$ & $0.38-77.37$ & $0.84-74.44$ & - & - & 0.04 \\
$\mathrm{Fe}$ & $3.21-548.32$ & $0.00-435.72$ & $1.16-375.27$ & - & 20.00 & 30.00 \\
\hline
\end{tabular}

UKEA= United Kingdom Environment Agency, NESREA= National Environmental Standards and Regulatory Agency, WHO=World Health Organization

*Range of metal content irrespective of extractants

Correlation ( $r$ ) studies: Result showed that EDTA strongly correlated positively with DTPA for Cd (0.960) alone, whereas it negatively correlated for $\mathrm{Zn}$ $(-0.895)$. The negative correlation for $\mathrm{Zn}$ indicated that soil properties affected the extraction of $\mathrm{Zn}$ by EDTA and DTPA, in that, despite having close $\mathrm{pH}$ and concentration, conditions that were favorable to EDTA efficiency were adverse for DTPA extraction of $\mathrm{Zn}$. With EDTA versus pseudo-total extractions, correlation existed only for $\mathrm{Cu}$ (0.999 for aqua regia and $\left.\mathrm{HNO}_{3} / \mathrm{HClO}_{4}\right)$ and $\mathrm{Cd}(0.807$ for aqua regia and 0.969 for $\left.\mathrm{HNO}_{3} / \mathrm{HClO}_{4}\right)$, which though was surprising, but not uncommon, as literature had reported such correlation for $\mathrm{Cu}$ (Ivezić et al., 2013). This observation was buttressed by earlier findings by Ivezić et al. (2013), in which they affirmed that EDTA and pseudo-total concentrations were not well correlated with concentrations in soil solution. They further maintained that the main reason for lack of 
correlation was due to the influence of soil properties, which played major role in solubility of trace metals.

It was interesting to observe that all extractants used in Cd extractions showed strong positive correlation at 0.05 or 0.01 significant levels. Such results suggest that there are not many other factors impacting $\mathrm{Cd}$ extractability.

Extractants variation with trace metals: The results of one-way ANOVA $(\mathrm{P}=0.05)$ showed that for farmlands, there were no significant differences in the mean $\mathrm{Cu}$ (0.612), $\mathrm{Pb}$ (0.149), $\mathrm{Cd}(0.338)$ and $\mathrm{Mn}$ (0.474) extracted by all solutions. However, Post Hoc test revealed that for $\mathrm{Zn}, \mathrm{Ni}$ and $\mathrm{Fe}$, at least one of the extractants must have differed significantly from the others in bringing the metals into solution. For mechanic workshops and dumpsites, no significant difference was observed in the mean metals extracted except for $\mathrm{Ni}$ and $\mathrm{Fe}$ in dumpsite, whose mean concentrations were influenced by extractants.

Interdependences of trace elements: Principal Component Analysis (PCA) was used to check for potential relationships between trace metals in soils collected from 7 farmlands. The analysis was based on correlation matrix and an accepted significance level of $<0.05$ was selected. The probability associated with the Bartlett's test was $<0.001$, which satisfied the requirement that it should be less than the level of significance (Bartholomew et al., 2008).
The Kaiser Criterion was used in choosing the number of components, and only factors with eigenvalues greater than 1 were retained (Jackson, 1991) while loadings greater than 0.9 were considered excellent and those less than 0.5 were unacceptable.

Total variance (\%), Factor loadings and number of significant factors that were explained by using Varimax with Kaiser normalized rotation method were presented in Table 6 . This rotation method was helpful in revealing the interaction of the various elements studied. PCA data indicated that a 2component solution (varifactors) would suffice to explain $73.96 \%$ of the total variance (Figure 1 and Table 6). The factor loadings (Table 6) showed that the first varifactor (factor 1) explained $55.54 \%$ of the total variance and loaded heavily on the positively corrected variables, describing $\mathrm{Zn}, \mathrm{Cu}, \mathrm{Pb}, \mathrm{Ni}, \mathrm{Cd}$ and $\mathrm{Fe}$ (range of loadings: 0.538-0.928). The second varifactor (factor 2) was only loaded primarily with negatively correlated Mn (loading was -0.862 ), which accounted for $18.42 \%$ of the total variance. It was observed that all elements in the varifactors except Mn showed strong positive correlation indicating that they must have been from the same source. The interrelationships among the elements in the varifactors space were shown as PCA plot (Figure 1). The plot indicated that the elements tend to cluster in groups of two or more. For example, pair of $\mathrm{Cd}-\mathrm{Cu}$ was linked with the first varifactor (Figure 1).

Table 6. Factors loading after varimax normalized rotation

\begin{tabular}{lcc}
\hline Element & Factor 1 & Factor 2 \\
\hline $\mathrm{Zn}$ & $\mathbf{0 . 7 7 2}$ & 0.441 \\
$\mathrm{Cu}$ & $\mathbf{0 . 9 0 6}$ & -0.082 \\
$\mathrm{~Pb}$ & $\mathbf{0 . 9 2 8}$ & 0.136 \\
$\mathrm{Ni}$ & $\mathbf{0 . 5 3 8}$ & 0.506 \\
$\mathrm{Cd}$ & $\mathbf{0 . 8 7 3}$ & -0.111 \\
$\mathrm{Mn}$ & 0.077 & $\mathbf{- 0 . 8 6 2}$ \\
$\mathrm{Fe}$ & $\mathbf{0 . 7 4 3}$ & 0.24 \\
$\mathrm{Variability}(\%)$ & 55.54 & 18.42 \\
Cumulative (\%) & 55.54 & 73.96 \\
\hline
\end{tabular}

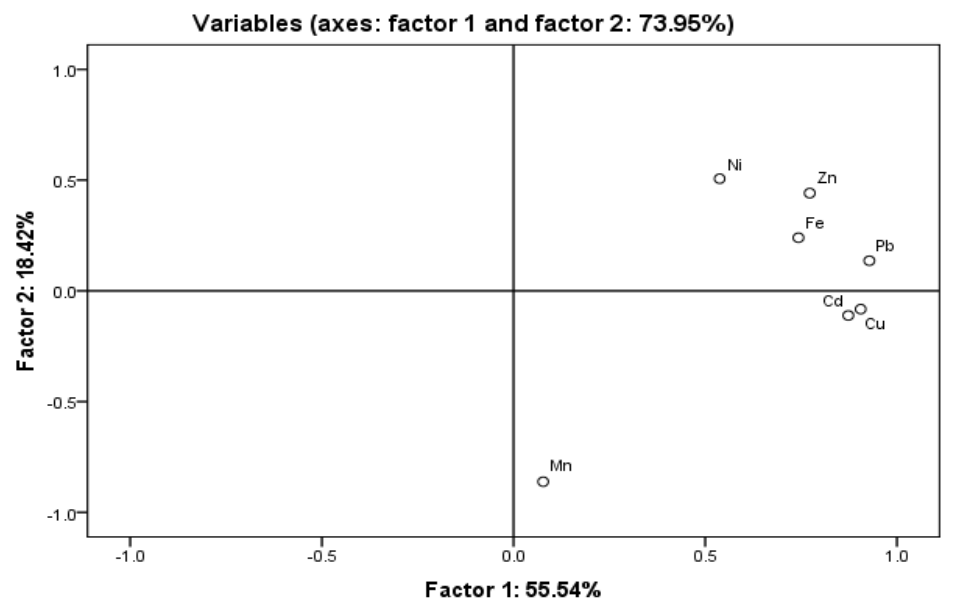

Fig 1. Plots of loadings (Varimax rotation) based on the concentrations of metals in soils in space of first and second varifactors

Conclusions: Selection of extractant and method of extraction entail taking into consideration the aim of the investigation, the origin and 'pool' of the extractable element, soil type and contamination source. Results of the analyses depicted that strong acid method $\left(\mathrm{HNO}_{3} / \mathrm{HClO}_{4}\right.$ and aqua regia), representing pseudo-total pool of trace metals in soil, showed good correlation between each other for all the investigated trace metals except $\mathrm{Zn}, \mathrm{Ni}$, and $\mathrm{Fe}$. Nonetheless, they showed no correlation with EDTA

$$
\begin{gathered}
\text { OMAKA, NDUKAKU OMAKA }{ }^{l} \text {, OFFOR, IFEANYI FRANCIS }{ }^{1} \text {, CHUKWU, EBUBE REBECCA }{ }^{2}, \text { EWUZIE, } \\
\text { UGOCHUKWU }{ }^{3}
\end{gathered}
$$


and DTPA except for $\mathrm{Cu}$ and $\mathrm{Cd}$, as well as $\mathrm{Pb}$ and $\mathrm{Cd}$ respectively. However, the method (EDTA and DTPA), which was employed to ascertain the bioavailable metals showed no correlation between each other for all metals except for positively correlated $\mathrm{Cd}$ and negatively correlated $\mathrm{Zn}$. Therefore, pseudo-total pool has implicated itself as poor indicator of bioavailability.

The results of this study indicate that the use of EDTA solution as extractant has at least two advantages: extracts are not corrosive and there is no need for further dilution. Furthermore, short time of sample preparation makes this method very convenient and acceptable, therefore, determination of trace metal bioavailability in soil becomes faster and relatively easy with EDTA extraction method.

Only $\mathrm{Cd}, \mathrm{Ni}$ and $\mathrm{Pb}$ had their values within the regulatory limits, whereas, others were above the limits in all samples from different locations. This raises significant environmental concern and calls for urgent attention and appropriate response. Stringent compliance to regulatory limits in waste to be discharged into dumpsites and mechanic workshops is advised.

\section{REFERENCES}

Adelekan, BA; Abegunde, KD (2011). Heavy metal contamination of soil and ground water at automobile mechanic villages in Ibadan, Nigeria. International journal of physical sciences 6(5): 1045-1058.

Sabienë, N; Brazauskienë, DM (2004). Determination of heavy metal mobile forms by different extraction methods EKOLOGIJA 1: 36-41

Idugboe, SO; Tawari-Fufeyin, P; Midonu, AA (2014). Soil pollution in two auto-mechanic villages in Benin City,

Nigeria. IOSR Journal Of Environmental Science, Toxicology And Food Technology (IOSR-JESTFT) 8(1): 09-14

Corbett, DR; Dillon, K; Burnett, W; Schaefer, G (2002). The special variability of nitrogen and phosphorous concentration in sand aquifer influenced by onsite sewage treatment and disposal systems: a case study on St.

George Island, Florida. Environmental Pollution. 117, 337 - 345 (2002)

Lindsay, WL; Norvell, WA (1978). Development of a DTPA soil test for zinc, iron, manganese, and copper. Soil

Science Society of America Journal. 42: 421 - 428.
Ivezić, V; Lončarić, Z; Engler, M; Kerovec, D; Singh, BR (2013). Comparison of different extraction methods representing available and total concentrations of $\mathrm{Cd}, \mathrm{Cu}, \mathrm{Fe}, \mathrm{Mn}$ and $\mathrm{Zn}$ in soil Poljoprivreda 19(1): 53-58

Bartholomew, DJ; Steele, F; Moustaki, I; Galbraith, JI (2008). Analysis of multivariate social science data (2nd ed.). CRC press.

Jackson, J.E. (1991). A User Guide to Principal Components. Wiley, New York.

Ancalulia, S (1999). Analytical studies on the pollution of Arges River. Critical Reviews in Analytical Chemistry 29(3): 243-247.

Antunović, M; Kovačević, V; Rastija, M; Zdunić, Z (2003). Influences of soil and genotypes on micronutrients status in maize plants. Poljoprivreda 9(1): 9-14.

Awoke, MU; Okorji, C (2004). Determination and analysis of constraints in resource use efficiency in multiple cropping systems by small-holders farmers in Ebonyi State, Nigeria. Africa Development 3(29): 58-69.

Chapman DE (1996). Water quality assessments-A guide to use of biota, sediments and water in environmental monitoring. $2^{\text {nd }}$ edition. University Press, Cambridge, pp.605-658.

Doumett, S; Lamperi, L; Checchini, L; Azzarello E, Mugnai S, Mancuso S, Petruzzelli G, Del BubbaM, (2008). Heavy metal distribution between contaminated soil and Paulownia tomentos $a$, in a pilot-scale assisted phytoremediation study: Influence of different complexing agents. Chemosphere 72(10): 14811490 .

Duffus, JH (2001). Heavy metals- A meaningless term. Chemistry International- Newsmagazine for IUPAC 23(6): 163-167

Eđed, A (2012). Genotype specificity of winter wheat (triticum aestivum l.) in cadmium, zinc and iron accumulation in grain. Poljoprivreda 18(1): 6575.

Feng, MH; Shan, XQ; Zhang, S; Wen, B (2005). A comparison of the rhizosphere-based method with DTPA, EDTA, $\mathrm{CaCl}_{2}$, and $\mathrm{NaNO}_{3}$ extraction methods for prediction of

$$
\begin{gathered}
\text { OMAKA, NDUKAKU OMAKA }{ }^{1} \text {, OFFOR, IFEANYI FRANCIS }{ }^{1} \text {,CHUKWU, EBUBE REBECCA }{ }^{2}, \text { EWUZIE, } \\
\text { UGOCHUKWU }
\end{gathered}
$$


bioavailability of metals in soil to barley. Environmental Pollution 137: 231-240.

Kim, ND; Fergusson, JE (1991). Effectiveness of a commonly used sequential extraction technique in determining the speciation of cadmium in soils. Science of the Total Environment 105: 191209.

Kovačević, V; Kadar, I; Koncz, J; Brkić, I; Banaj, D (2002). Cadmium and lead status in corn hybrids grown on acid soil of eastern Croatia. Poljoprivreda 8(1): 10-14.

Nouri, J; Mahvi, AH; Babaei, A; Ahmadpour, E (2006). Regional pattern distribution of groundwater fluoride in the Shush aquifer of Khuzestan County Iran. Fluoride 39(4): 321-325.

O'Connor, GA (1988). Use and misuse of the DTPA soil test. Journal of Environmental Quality 17: 715-718.

Omaka, ON (2010) Atmospheric and Metallic Pollutants and their impacts on the Environment: Case Studyof Abakaliki Metropolis. Journal of Applied and Natural Sciences 4(1): 24-29.
Peijnenburg, WJGM; Zablotskaja, M; Vijver, MG (2007). Monitoring metals in terrestrial environments within a bioavailability framework and a focus on soil extraction. Ecotoxicology and Environmental Safety 67(2): 163-179.

Rieuwerts, JS; Thornton, I; Farago, ME; Ashmoret, MR (1998). Factors influencing metal bioavailability in soils: Preliminary

investigations for the development of a critical loads approach for metals. Chemical Speciation and Bioavailability 10: 61-75.

Sun, B; Zhao, FJ; Lombi, E; McGrath, SP (2001). Leaching of heavy metals from contaminated soils using EDTA. Environmental Pollution 113(2): 111-120.

Yongming, H; Peixuan, D; Junji, ES; Posmentier, ES (2006). Multivariate analysis of heavy metal contamination in urban dusts of Xi'an, Central China. Science of the Total Environment 355(13): 176-186. 